\title{
Growth rate in CXC STEM subject entries: Implications for meeting the development needs of the Caribbean
}

\author{
Stafford A. Griffith ${ }^{1}$ \\ University of the West Indies, Jamaica
}

\begin{abstract}
After years of emphasizing the need to prepare students with skills acquired though the study of science, technology, engineering and mathematics (STEM) for the demands of the job market and to support economic development, there is a need to assess the extent to which subject entries for end of secondary school examinations in the Caribbean reflect change in this direction. Such an assessment was undertaken by examining the extent to which students are taking STEM clusters of subjects in the May/June Caribbean Secondary Education Certificate (CSEC) examinations of the Caribbean Examinations Council (CXC). It was found that the number and percentage of entries for STEM subjects was higher than those for the overall CSEC subject entries. A low rate of positive growth was noted in many clusters of STEM subjects along with periods of negative growth. It was concluded that, at best, the growth rate in STEM subject entries was anaemic. In view of the importance of the STEM subjects in preparing secondary school students both for the world of work and for advanced studies that will provide critical advanced skills required in the work force of the twenty-first century, more effective policy and policy implementation in education must be pursued in the Region to ensure a sharper focus on STEM education at the secondary level.
\end{abstract}

Keywords: STEM education, secondary education, Caribbean Examinations Council, Caribbean development, education policy.

\section{Background and Purpose}

\section{Value of STEM Education}

The extent to which the school curriculum is placing emphasis on science, technology, engineering and mathematics (STEM) education is now a fundamental global concern (Donovan, Mateos, Osborne, \& Bisaccio, 2014; Merchant, Morimoto, \& Khanbilvardi, 2014). This is due to the widely held view that the growth of economies worldwide requires the types of innovation and skills which STEM education provides (Corlu, Capraro, \& Capraro, 2014; Kuenzi, 2008; OECD, 2010; UNESCO, 2009). Progress in science, technology, engineering and mathematics is therefore seen as a catalytic force for innovation-driven growth (National Academy of Sciences, National Academy of Engineering \& Institute of Medicine, 2011). It is not surprising that in today's world, an increasing number of jobs are requiring STEM-related competencies (Jang, 2016; Lacey \& Wright, 2009).

Access to programs of study in STEM-related areas is considered important for the development of skills that are in demand and that will allow individuals to contribute to, and benefit from, the technologically driven economic development programme which characterise nation building in the twenty-first century (Jang, 2016; Padro, 2010; Pawloski, Maas, Meyers, Standridge,

${ }^{1}$ Corresponding author: Office for Online Learning, Vice Chancellery, University of the West Indies, Mona Campus, Kingston, Jamaica, E-mail: drstaff@yahoo.com

Griffith, S. A. (2019). Growth rate in CXC STEM subject entries: Implications for meeting the development needs of the Caribbean. Journal of Research in STEM Education, 5(2), 138-150. 
\& Plotkowski, 2010). The focus of the school curriculum on STEM education will prepare students, better, for both direct entry into the world of work and advanced studies that will provide critical skills required in the work force of the twenty-first century. (Beede et al., 2011; Corlu et al., 2014; Evans, McKenna, \& Schulte, 2013; Lacey \& Wright, 2009). It is therefore not surprising that there is renewed interest in STEM education worldwide. In the United States, this renewed interest might have arisen out of the concern that the results on international tests in science and mathematics, in particular, had ranked that country below a number of its competitors and the implications that this would have for the global competitiveness of the United States (Eberle, 2010; Kuenzi, 2008; Sanders, 2009). This was the concern that prompted the following statement by Arne Duncan, then United States Secretary of Education:

Everyone has a stake in improving STEM education. Inspiring all our students to be capable in math and science will help them contribute in an increasingly technologybased economy, and will also help America prepare the next generation of STEM professionals-scientists, engineers, architects and technology professionals - to ensure our competiveness. (U.S. Department of Education, 2010)

There is an evident concern in Europe, as well, about the need to expand and improve STEM education to assure competitiveness of the national and regional economies (Kudenko \& GrasVelázquez, 2014; Rohaan, Taconis, \& Jochems, 2010). A number of studies show that in Europe, steps are being taken to increase students' interest in STEM studies and careers. These include improved pedagogical approaches to give students a better understanding of the relevance of STEM to life and the world of work, and engaging students in awareness-raising activities around STEM jobs (Joyce, 2014; Kudenko \& Gras-Velázquez, 2014; Rohaan et al., 2010).

In the Caribbean, there is also a new interest in STEM education. This is due to a recognition of the need to develop a pool of skills that will facilitate the best use of the Region's comparative advantage, as well as to encourage and support investment that will help to grow the Region's economy out of the debt which constrain development in many Caribbean countries. Warde and Sah (2014), in an article on STEM education considerations in the Caribbean, made the point that STEM education, coupled with entrepreneurial education, is a necessary path for Caribbean countries in order to work their way out of their current indebtedness. STEM education is important to the future economic prosperity of countries in the Region.

However, a World Bank report on the Organization of Eastern Caribbean States (OECS) - a sub-grouping of Caribbean countries - notes that only a few of the less than 15 percent of students who attend post-secondary education in the OECS, enroll "in programs that are considered to be in high demand (i.e. Sciences, Engineering, Mathematics)" (World Bank, 2013, p. 6). According to the report, school leavers in the Caribbean struggle to find formal employment due to a mismatch between the education they receive in the region and the demands of the job market. The report suggested that systemic changes are required in the education provided to students in the Caribbean so that they may acquire skills that would help them to find a place in the job market (World Bank, 2013). This is a clear call for action to reform the education system to focus more on the skills that are required in the job market. These are, essentially, STEM-related skills.

There is an obvious need for more students to pursue STEM-related programmes. This is particularly so for those who are completing their final years of school since most of them will enter the job market with expectations of securing early employment. The lack of appropriate skills may leave many disappointed with the need to retool to acquire competencies which they could have acquired prior to leaving school, had the focus of the curriculum been on STEM-related preparation.

A few countries in the Region have been attempting a more focussed, systemic approach in addressing the issue of better preparation of students with the competencies that are required for the job market. Jamaica provides a good example of such recent efforts. In full recognition of the need to re-focus the curriculum in schools, the Ministry of Education in Jamaica has recently embarked on a programme to infuse a STEM methodology into the curriculum at all levels of its education system 
and to concentrate on the development of specialized STEM skills for students in their final years of secondary education. According to the Ministry, the plan is to "transform selected High Schools into STEM Academies and to incorporate STEM methodology in all schools" (Ministry of Education, Jamaica n.d., p. 1). The Jamaica Observer newspaper of November 20, 2015, in an article titled STEM curriculum to roll out in schools next year, citing statements from the Ministry of Education, Jamaica, reported that "the incorporation of Science, Technology, Engineering and Mathematics (STEM) methodologies in the curriculum of schools will be rolled out in the 2016 academic year". The newspaper further pointed out that the subjects will be taught to students at the Grades One to Nine levels in primary and secondary institutions and noted that nine High Schools had already been specifically selected to be transformed into STEM academies.

These are recent initiatives whose success will have to be assessed at some future date. A more current concern is the extent to which the importance of the discussions over the last few years about the need for a greater focus in the Region on equipping students with STEM-related skills to meet the demands of the job market and to support economic growth and development is reflected in the programmes being pursued by students. This concern is particularly important for those students who are completing their last years of secondary school since most of them are imminent entrants to the job market.

The issue, therefore, is whether the Caribbean education system has been preparing secondary school graduates to meet the current and future demands for expertise in science, technology, engineering and mathematics. An examination of the extent to which students at the end of secondary school level are pursuing certification in STEM-related subjects would shed light on this matter.

\section{Role of CXC and Reciprocal Responsibility of Territories}

The Caribbean Examinations Council (CXC) plays an important role in defining the nature of the education provided to secondary school students in the Caribbean, and in particular those students pursuing secondary school completion for various destinations in employment and further education. These students prepare for, and take a mix of subjects in the Caribbean Secondary Education Certificate (CSEC) Examinations in keeping with their interests.

Article III (a) of the Agreement Establishing the Caribbean Examinations Council (1972) charged the Council with conducting "such examinations as it may think appropriate" and awarding "certificates and diplomas on the results of the examinations so conducted". With this mandate, the Council is expected to play a leading role in assuring an education for students that is fit for the purpose of Caribbean regional development.

Given the importance of STEM subjects in providing the pool of competencies to support regional development, it is reasonable to expect that the offerings of CXC will reflect an emphasis on courses of study and related examinations in science, technology, engineering and mathematics. There is, of course, a corollary obligation, on the part of participating member-territories of CXC to emphasize in their respective schools, the preparation of students in these areas. This should be reflected in larger numbers of entries for clusters of subjects in science, technology, engineering and mathematics among those taken by students.

\section{Purpose of the Study}

After years of articulating the importance of preparing Caribbean students with skills that are critical for the job market, including skills acquired through the study of science, technology, engineering and mathematics, it is necessary to assess the extent to which subject entries of students in the end of secondary school examinations reflect progress in this direction. This study sought to assess the extent to which students preparing to exit the secondary education system were taking the STEM-related clusters of subjects in the end of secondary school May/June CSEC examinations of CXC. 


\section{Method and Procedures}

\section{Research Questions}

The following two related research questions guided this investigation:

1. To what extent does the number and proportion of entries for STEM-related subjects in the CSEC examinations of CXC reflect a positive change in popularity of these subjects among students at the end of secondary school level?

2. To what extent does the growth rate in entries for STEM-related subjects in the CSEC examinations reflect changes that are consistent with increasingly higher value being placed on these subjects by students at the end of secondary school level?

\section{Sampling}

The study utilized a purposive total population sampling approach (Emerson et al., 2001; Kyaga, Lichtenstein, Boman, \& Landen, 2015; Langstrom, Frisell \& Lichtenstein, 2011; Krokstad, Kunst, \& Westin, 2002). This type of sampling is not frequently used in educational research where large populations are involved. A representative sample is usually drawn from the population and inferences made to the population based on findings from the sample. In the current study, the data were fully and easily accessible for the total population with the characteristics with which the study was concerned.

\section{Definition of Terms}

For this investigation, the STEM-related subjects comprised clusters of subjects which may be classified as science, technology, engineering and mathematics clusters, selected from the full offerings of subjects in the CXC CSEC examinations. In the rest of this article, these will be referred to as STEM subjects or STEM clusters of subjects, as appropriate. The science cluster of subjects comprised the three subjects in the single sciences. These are CSEC Chemistry, CSEC Biology and CSEC Physics. The syllabuses for all three subjects emphasize skills of using scientific concepts and principles to resolve issues. The syllabuses for these subjects aim to develop investigative and problem-solving skills as well as skills of ethical conduct, team work, critical thinking, innovation and effective communication of scientific information (CXC, 2006; 2013a, 2013b). Clearly, these are the type of skills that students who have completed their secondary education would need for the job market.

The technology cluster of subjects in this study comprised offerings in the following five subjects: Building Technology - Construction, Building Technology - Woods, Technical Drawing, Information Technology, and Electronic Document Preparation and Management. The Building Technology - Woods, and Building Technology - Construction syllabuses focus on the acquisition of knowledge, skills and attitudes needed for employment at entry level in the wood and construction industries, respectively. They provide practical experiences that will enable students to develop skills in the use of tools, materials and processes associated with the woods industry (CXC, 2015a). The Technical Drawing syllabus provides foundational skills useful for careers in drafting, architecture, surveying, civil engineering, interior designing, design engineering and the general construction and manufacturing industries (CXC, 2015b). The Information Technology syllabus emphasizes the development of proficiency in the use of productivity tools (CXC, 2008a) while the Electronic Document Preparation and Management syllabus is designed to equip students with knowledge and computer-related skills required to enhance the performance of clerical and administrative tasks (CXC, 2012). These technology subjects will also help students to develop critical job market competencies.

For this investigation, the engineering cluster of subjects comprised two CSEC offerings Electrical and Electronic Technology, and Mechanical Engineering Technology. These subjects target the acquisition of the knowledge, skills and attitudes needed for employment at the entry level, 
including practical experiences, in fields related to the discipline (CXC, 2015a). The competencies they seek to develop are directly linked to the job market.

For this investigation, the mathematics cluster of subjects comprised CSEC Mathematics and CSEC Additional Mathematics. The Mathematics syllabus seeks to prepare students for the use of specific mathematical techniques in future careers, for example, in agriculture and in commercial and technical fields (CXC, 2008b). The Additional Mathematics syllabus builds on the foundation provided in CSEC Mathematics and emphasizes skills of logical reasoning. Students completing this subject are expected to be in a position to make a smooth transition to higher levels of study in mathematics, or move on to career choices where a deeper knowledge of mathematicsis required (CXC,2010). These two mathematics subjects provide the foundations to do well in a wide range of jobs and in the Caribbean at least one of them is usually required for most entry level jobs sought by secondary school graduates.

Data for the Study

Two sets of data were required for this study. The first set of data comprised the total population of candidates in the 16 CXC member-countries who took the CSEC examinations in the 15 selected STEM clusters of subjects over the nine year period 2006 to 2014. The second set of data comprised the total population of candidates in the 16 CXC member-countries who took all 34 CSEC subject examinations offered over the nine year period 2006 to 2014 . The aggregated candidate entries across the $16 \mathrm{CXC}$ member-countries for each of nine years for both the first and second set of data were extracted from a soft copy of CXC's annual Statistical Bulletin for the years 2006 to 2014. These candidate entries formed the primary sources of data for the study.

Procedures

The CXC Statistical Bulletin contains examinations data which the Council provides to its member-countries. It is provided as a soft copy on an external storage device such as a compact disc or a USB flash drive. The data provided includes subject entries and results for the current and past years. Some types of data are provided for a five year period.

The data for the study were drawn from more than one annual Statistical Bulletin and compiled to provide the data required for the study. With the use of EXCEL Pivot Tables, the reports required for the study were generated and exported into Microsoft Word where refinements were made to ensure satisfactory and consistent format of tables and graphs which summarised the findings and enhanced data analysis.

\section{Results}

\section{Number and Proportion of CSEC Entries for STEM Subjects}

Figure 1 shows a comparison of the absolute number of subject entries for all CSEC subjects for the nine years, 2006 to 2014 and those for the STEM cluster of subjects. It shows that there was an annual increase in overall CSEC subject entries between 2006 and 2012. In 2006, there were 536,910 entries. By 2012 this had increased to 634,678. This represents an increase of 18.21 percent over that period.

In the case of the combined entries for the STEM cluster of subjects, there was a steady increase between 2006 and 2012 - from 174,001 in 2006 to 215,462 in 2012. This represents an increase of 23.83 percent over that period. The figure shows, however, that in the post 2012 period both overall entries and entries for the STEM cluster of subjects declined. Overall subject entries declined from the 634,678 in 2012 to 602,333 in 2014, a decline of 5.10 percent. The decline for the combined STEM entries in the same period was from the 215,462 in 2012 to 212,114 in 2014 . This represents a decline of 1.55 percent over that period. 
700000

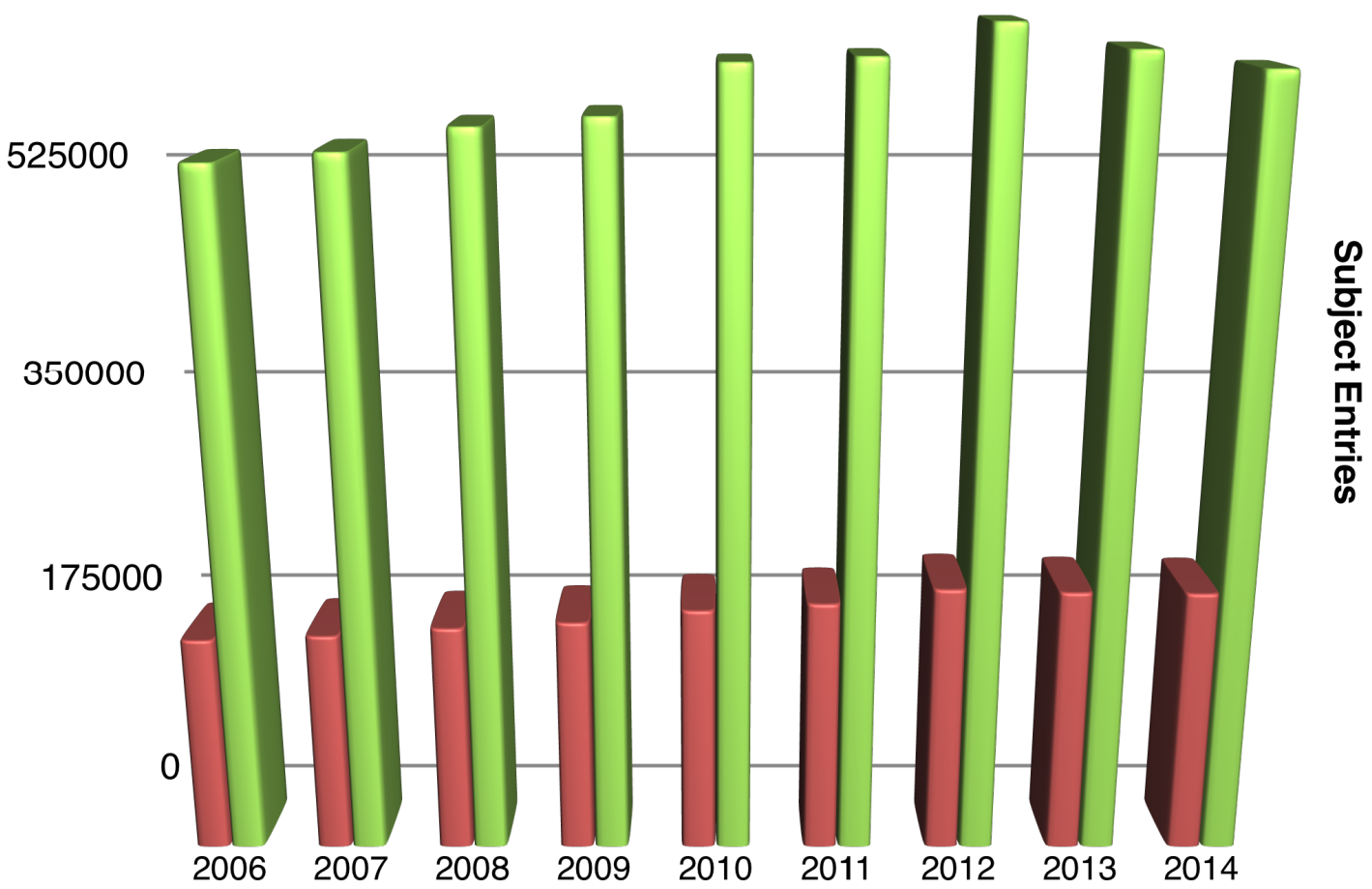

Figure 1. Comparison of overall subject entries and total STEM subject entries for the period 2006 to 2014

Evidently, in the years when there was an increase in both the overall subject entries and the combined entries for the STEM cluster of subjects, the percentage increase in the entries for the STEM cluster of subjects was larger than that of the overall entries. Also, during the period of decline which was shared in common by the overall entries and the entries for the STEM cluster of subjects, the decline was less pronounced for the STEM cluster of subjects than for the subjects overall.

This would suggest that over the nine year period, there was a more favourable increase in the entries for STEM clusters of subjects compared with the overall CSEC entries. However, this seemingly favourable assessment of the STEM cluster of subjects must be tempered by the consistently small proportion of students who took the STEM subjects in each of the nine years. These proportions are reflected in Figure 2.

Figure 2 shows that STEM subject entries as a proportion of overall subject entries for the CSEC examinations ranged from 35.22 percent of the overall entries (in 2014) to 32.41 percent (in 2006). The mean percentage across the nine year period was 33.43. The figure shows that since 2006, there has been a steady annual increase in the proportion of CSEC STEM subject entries. The only exception in the nine year period was a small decrease in 2010 to 32.68 from 33.10 in 2009. This shows that the STEM subjects entries as a percentage of the overall CSEC subject entries had an upward trajectory. 


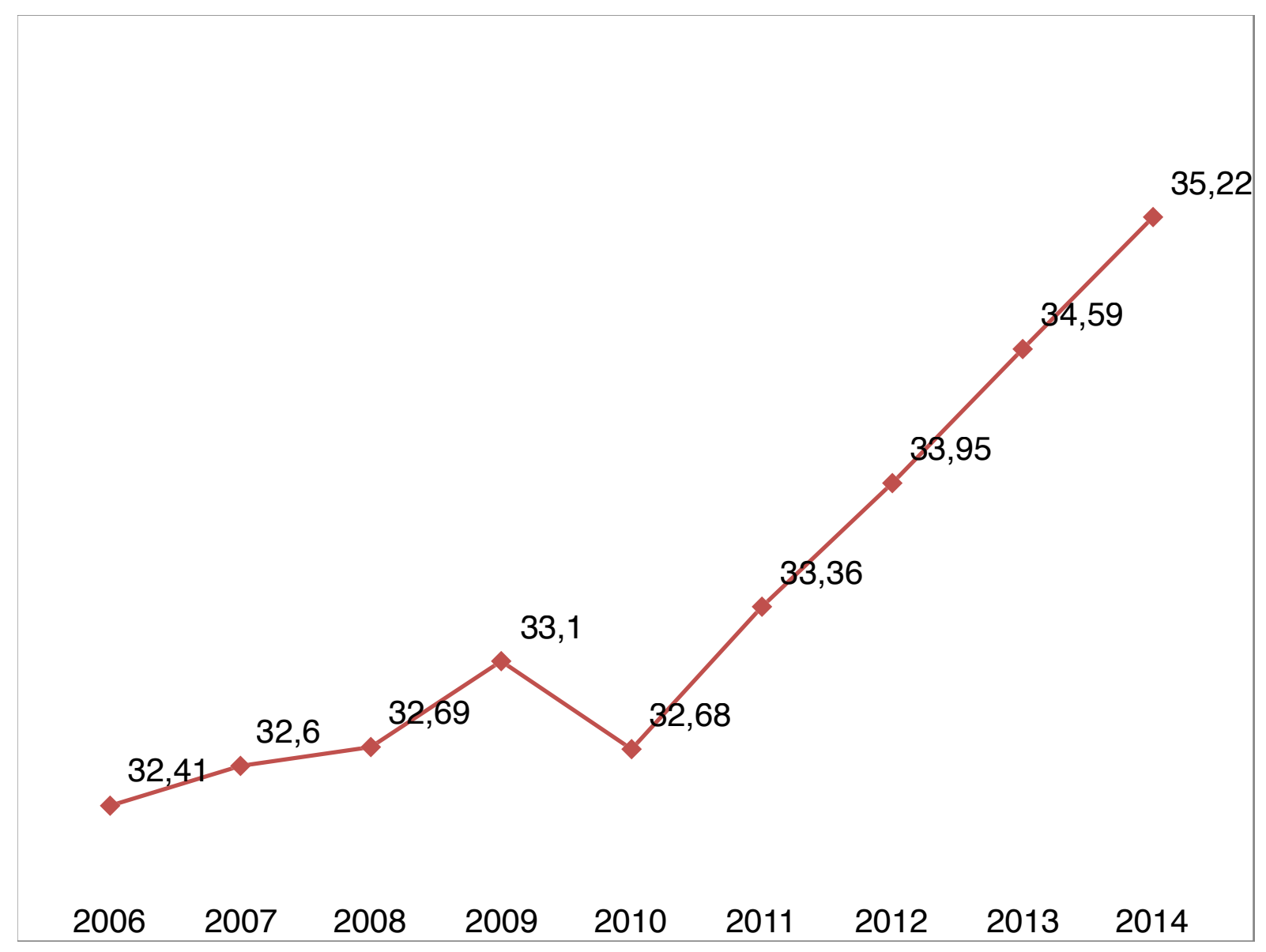

Figure 2. Percentage of STEM subject entries over the nine year period 2006 to 2014

However, it is important to note that over the nine year period, the proportion of increase for the STEM cluster of subjects was no more than 2.81 percentage points - from 32.41 percent in 2006 to 35.22 percent in 2014. Given the importance of STEM subjects in meeting job market needs in the Region and in catalyzing development, such a small increase in the proportion of end of the secondary school population taking STEM subjects cannot be regarded as satisfactory.

Growth Rate in Entries for STEM Subjects

Table 1 shows that growth rate for the overall CSEC entries, that is, for the 34 CSEC subjects, ranged from 6.18 percent (in 2009-2010) to -3.08 percent (in 2012-2013). The mean growth rate for these subjects over the nine year period covered by the study was 1.39 percent. The Table shows that for the 15 STEM subjects, combined, the growth rate ranged from 5.43 percent (in 2011-2012) to -1.38 (in 2012-2013). The mean growth rate for these subjects over the nine year period was 2.40 percent.

For all years except one, the growth rate for the combined STEM subject entries was better than the growth rate for the overall CSEC subject entries. The exception was 2009-2010 when the overall CSEC entries grew by 6.18 percent compared with 4.97 percent for the combined clusters of STEM subjects. It is evident that 2010 was an anomalous year. This was already noted in the previous section when considering the number and proportion of CSEC entries for STEM subjects. 
Table 1.

Comparison of the growth rate of STEM subject entries and overall CSEC subject entries for the period 20062014

\begin{tabular}{ccccccc}
\hline \multirow{2}{*}{ Year } & \multicolumn{5}{c}{ Entries for STEM Subjects } & \multirow{2}{*}{$\begin{array}{c}\text { Overall } \\
\text { Entries }\end{array}$} \\
\cline { 2 - 5 } & Science & Technology & Engineering & Mathematics & Combined & \\
\hline $2006-2007$ & $0.58 \%$ & $7.35 \%$ & $5.29 \%$ & $-0.15 \%$ & $1.97 \%$ & $1.38 \%$ \\
$2007-2008$ & $0.97 \%$ & $9.47 \%$ & $-4.09 \%$ & $1.80 \%$ & $3.42 \%$ & $3.17 \%$ \\
$2008-2009$ & $3.67 \%$ & $6.58 \%$ & $6.98 \%$ & $-0.42 \%$ & $2.50 \%$ & $1.27 \%$ \\
$2009-2010$ & $7.51 \%$ & $1.18 \%$ & $4.35 \%$ & $5.87 \%$ & $4.97 \%$ & $6.18 \%$ \\
$2010-2011$ & $5.87 \%$ & $3.84 \%$ & $-2.83 \%$ & $0.97 \%$ & $2.65 \%$ & $0.65 \%$ \\
$2011-2012$ & $7.11 \%$ & $2.79 \%$ & $3.54 \%$ & $6.13 \%$ & $5.43 \%$ & $3.75 \%$ \\
$2012-2013$ & $1.82 \%$ & $-1.55 \%$ & $-1.18 \%$ & $-2.34 \%$ & $-1.38 \%$ & $-3.08 \%$ \\
$2013-2014$ & $1.55 \%$ & $2.78 \%$ & $-1.76 \%$ & $-2.97 \%$ & $-0.40 \%$ & $-2.22 \%$ \\
\hline Mean Rate & $3.64 \%$ & $4.05 \%$ & $1.29 \%$ & $1.11 \%$ & $2.40 \%$ & $1.39 \%$ \\
\hline
\end{tabular}

It is evident from Table 1 that of the four clusters of STEM subjects, it was only the science cluster which experienced sustained though uneven growth over the 2006 to 2014 period. There was one year of negative growth for the technology cluster of subjects, that is, in 2012-2013. The engineering and mathematics clusters both showed negative growth in four of the eight periods. These two clusters of subjects shared negative growth for identical periods on two occasions, 20122013 and 2013-2014. These were the same years that the combined STEM entries and the overall entries showed negative growth.

Except for the first two years (2006-2007 and 2007-2008) growth in entries for the science cluster of subjects was consistently better than growth in the overall CSEC entries. No similar pattern existed for the other clusters of subjects. In five of the eight years, the technology cluster of subjects showed a growth rate higher than that of the corresponding overall CSEC growth rate. Three of these were in the first three years (2006-2007, 2007-2008 and 2008-2009) while the others were in the last two years (2012-2013 and 2013-2014). For the engineering cluster, there was higher growth rate in four instances than in the corresponding overall CSEC growth rate (2006-2007, 2008-2009, 20122013 and 2013-2014). In the case of the mathematics cluster, the growth rate was higher than for the overall CSEC entries in only three corresponding years (2010-2011, 2011-2012 and 2012-2013).

\section{Discussion}

The study sought to assess the extent to which students preparing to exit the secondary education system were taking the STEM cluster of CXC subjects. In this study, the science cluster of subjects comprised the three CSEC single-science subjects - Biology, Chemistry and Physics; the technology cluster comprised the CSEC offerings in Building Technology - Construction, Building Technology - Woods, Technical Drawing, Information Technology, and Electronic Document Preparation and Management; the engineering cluster comprised two CSEC offerings - Electrical and Electronic Technology, and Mechanical Engineering Technology; and the mathematics cluster comprised CSEC Mathematics and CSEC Additional Mathematics.

The research used a purposive total population sample. It utilized two sets of data. The first was the total population of candidates in the $16 \mathrm{CXC}$ member-countries who took the 15 selected CSEC STEM subject examinations over the nine year period 2006 to 2014. The second was the total population of candidates who took all 34 CSEC subject examinations offered in the 16 CXC membercountries over the same period.

The first research question was concerned with the extent to which the number and proportion of entries for the CSEC STEM cluster of subjects reflected a positive change in popularity of these subjects among students at the end of secondary school level. It was found that for the first seven 
years covered by the study (2006 to 2012) there was a steady increase in the number of candidates taking STEM subjects. The increase ranged from 174,001 in 2005 to 215,462 in 2012. This provided some evidence of increased popularity of STEM subjects over that period. After 2012, there was a decline in the number of students taking STEM subjects - 212,967 in 2013 and 212,114 in 2014.

A similar pattern of growth and decline was noted for the overall entries in the CSEC examinations. However, the percentage increase in entries in the period of growth was higher for the STEM clusters of subjects than for the overall entries in CSEC subjects. Also, during the period of decline, the decrease in entries for the STEM cluster of subjects was less severe than for the overall CSEC subject entries. For the STEM clusters, there was a 23.83 percent increase in entries between 2006 and 2012, compared with 18.21 percent for the same period for overall CSEC entries. The decline in entries over the period 2012 to 2014 was 1.55 for STEM subjects, compared with 5.10 for the overall CSEC subject entries.

It is likely that the downward trend in numbers for both the overall entries and the STEM entries between 2012 and 2014 was due to the economic challenges which many Caribbean countries experienced from the delayed effects of the widely discussed global recession of 2008 (MercerBlackman \& Melgarejo, 2013). A recent United Nations report explained the challenge emanating from the global recession for developing countries such as those in the Caribbean. According to the report:

During 2012, global economic growth has weakened further. A growing number of developed economies have fallen into a double-dip recession. Those in severe sovereign debt distress moved even deeper into recession, caught in the downward spiralling dynamics from high unemployment, weak aggregate demand compounded by fiscal austerity, high public debt burdens, and financial sector fragility. (UN, 2013, p. 1)

This summarises well, the post 2012 circumstance of most Caribbean countries. It is likely that these circumstances affected the capacity of a number of parents to meet the cost of financing their children for the CSEC examinations and is therefore likely to be a significant contributory factor in the decline of the overall entries for CSEC examinations from 2012.

The growth and decline figures for the STEM cluster of subjects and the overall CSEC examinations, taken together, suggest that over the nine year period, there was a more favourable, though small, increase in the entries for the STEM cluster of subjects than in the overall CSEC entries.

Over the nine year period covered by the study, combined STEM subject entries, as a proportion of overall CSEC subject entries, ranged from 32.41 percent in 2006 to 35.22 percent in 2014. In fact, the combined STEM subject entries as a proportion of overall CSEC entries had an upward trajectory across the nine years. The only exception to a steady increase in the proportion of STEM subject entries across years occurred in 2010 when STEM subject entries as a proportion of overall CSEC subject entries declined from 33.10 percent in the previous year to 32.68 percent.

The increasing proportions of STEM subject entries, though a positive finding for the STEM cluster of subjects, must be interpreted with caution. These proportions are not as large as one would reasonably expect if indeed STEM subjects were being given the expected preference as preparation for employment and further studies in relevant high demand areas as advocated by many (Corlu et al., 2014; Lacey \& Wright, 2009; Ministry of Education, Jamaica, n.d.; Padro, 2010; UNESCO, 2009; World Bank, 2013).

If students were responding to the espoused importance of STEM subjects in providing education fit for the purpose of educating them for both the existing skill demands in the employment sector and their preparation for advanced studies in high demand areas in the work force, the numbers and proportion pursuing the STEM subjects should have been much larger. One would reasonably expect the entries of the 15 STEM subjects considered in this investigation to represent well over 50 percent of the subject entries for the 34 CSEC subjects.

The second research question was concerned with the extent to which the growth rate in entries for STEM subjects in the CSEC examinations reflect changes that are consistent with 
increasingly higher value being placed on these subjects by students at the end of secondary school level. The nine year period covered by the study allowed for eight periods over which growth rate could be considered.

It was found that for all periods, except one, the growth rate for the combined STEM subject entries was better than the growth rate for overall CSEC entries. The exception was in 2009-2010 when the combined STEM subjects grew by 4.97 percent compared with overall CSEC entries which grew by 6.18 percent. This growth of STEM subject entries at a higher rate than the overall CSEC entries is consistent with what may be reasonably expected, given the importance attached to STEM subjects.

Growth rate for the various clusters of STEM subjects, as well as for the combined STEM clusters fluctuated at a low level over the nine years and no pattern or trend was evident. The growth rate for the technology cluster was positive for seven of the eight periods covered in this study and higher than the growth rate for the CSEC overall entries for six of the eight periods. The mean growth rate of 4.05 percent across the eight periods for this STEM cluster of subjects was, in fact, higher than that of any other cluster. This is noteworthy. This might well be an indication that students at the end of secondary school level are responding positively to the growing demand in the job market for competencies associated with these subjects.

Though the mean growth rate of 3.64 percent for the science cluster of subjects over the eight periods covered by the study was not as high as that for the technology cluster, it was only this cluster that showed sustained positive growth over all eight periods covered by the study. Except for the first two periods (2006-2007 and 2007-2008), growth rate in the Science cluster of subject was consistently better than the growth rate in the overall CSEC subjects entries. There was no parallel finding for any other clusters of subjects.

While the science cluster, like the technology cluster might well be responding to the job market demands, there is at least one other consideration that may be influencing the growth rate of the science cluster of subjects. The science cluster forms a critical offering in the more prestigious secondary schools in the Caribbean. As Griffith (2013a) noted, these are subjects that larger numbers of high performing students are likely to pursue. Because of the accepted value of these subjects, parents are more likely to make the sacrifice in difficult economic circumstances to finance the cost of the examinations in these subjects. This matter was discussed earlier when considering the findings in relation to the first research question.

The growth for mathematics, a gateway cluster not only for other STEM clusters of subjects, but also for several other areas of study, was negative for half of the eight periods covered in the study. The mean growth rate for the periods was merely 1.11 percent which was below the mean growth rate for the overall CSEC entries. Only in three of the eight periods did the growth rate for the mathematics cluster exceed the growth rate for the overall CSEC entries.

The centrality of mathematics in secondary education generally, and in STEM education specifically, would lead to the reasonable expectation that there would be a sustained, and increasing, positive growth rate in this cluster of STEM subjects and that the growth rate would be higher than that of the overall CSEC subject entries. This is a matter of grave concern which needs to be addressed in the Region if the Caribbean is to turn out graduates with the competencies that this cluster of STEM subjects provides and which are important for the development of skills required in a technologically driven economic development programme which is important for nation building in the twenty-first century (Padro, 2010).

Like the mathematics cluster, the growth rate of the engineering cluster of subjects was negative for half of the eight periods covered in the study. The mean growth rate of 1.29 percent for this cluster of subject was only marginally better than that of the mathematics cluster and, like the mathematics cluster, fell below the mean growth rate for the overall CSEC entries. Also, it was only in four of the eight periods that the growth rate for the engineering cluster exceed the growth rate for the overall CSEC subject entries. 
The subjects in the engineering cluster (Electrical and Electronic Technology, and Mechanical Engineering Technology in this study) target the acquisition of the knowledge, skills and attitudes needed for employment at the entry level, including practical experiences, in fields related to the discipline (CXC, 2015a). These are competencies directly linked to the job market and which are essential for the national development programmes of the Region. The slow rate of growth is a matter that requires urgent attention in the Region.

Taking into account the emphasis placed on the STEM subjects to meet the job market demands and to support sustained economic growth in the Region (World Bank, 2013), the rate of growth for the STEM cluster of subjects could not be deemed satisfactory. The growth rate is, at best, anaemic. At the observed average rate of growth of 2.40 percent for the combined STEM cluster of subjects, it would require 30 years to achieve a doubling of entries! This is clearly untenable to meet the development needs of the Region. A doubling of the entries of these subjects over a three to five year period would be a reasonable expectation. That will require a growth rate of 24.0 to 14.4 percent.

Ritz and Fan (2015) pointed to the fact that, in many countries, although there have been continued discussions about STEM education, little action has been taken to modify educational systems to deliver this form of education. This appears to be true of the Caribbean. There is an evident need for a more effective policy on STEM education in the Region.

\section{Conclusion and Recommendations}

There can be no denying that STEM education is important for the preparation of secondary school students both for the world of work and for advanced studies that will provide critical advanced skills required in the work force of the twenty-first century. (Corlu et al., 2014; Lacey \& Wright, 2009). More must be done in the Caribbean to reflect an awareness of this reality.

More effective policy and policy implementation in education must be pursued in the Region to ensure a sharper focus on STEM education at the secondary level. Policy implementation would need to be buttressed by a dynamic public education programme. In this regard, the following views expressed by one Caribbean author are worthy of consideration:

Despite years of educational reforms and redirection of educational investment to generate secondary school graduates to meet our development needs, the performance of students, teachers and schools still seems to be judged by performance in subjects associated with the ancient grammar school education. Perhaps, this is a case of repetition conquering reason. Those who have been castigating students, teachers and schools have been so vociferous that they seem to have shouted down the reformers, and even those in the employment sector now seem to have forgotten what they really need. They too, seem to have joined the chorus in calling for success in the traditional grammar school subjects for entry level employment. We seem to have lost our way. (Griffith, 2013b, p. 28)

A more positive response to the STEM initiatives in the Caribbean, and improvement in the popularity of STEM clusters of subjects in the CXC examinations, will require extensive public education to help parents, teachers, students and employers to appreciate the value of STEM education for employment of secondary school graduates and for the economic advancement of countries in the Region. It will require, as well, an appropriate shift in educational policy by many Caribbean countries to improve the number and proportion of secondary school students who graduate with STEM subjects. 


\section{References}

Agreement Establishing the Caribbean Examinations Council. 1972. Article III (a).

Beede, D.N., Julian, T.A., Langdon, D., McKittrick, G., Khan, B., \& Doms. M.E. (2011). Women in STEM: A Gender Gap to Innovation. Economics and Statistics Administration Issue Brief No. 04-11. Retrieved from http://ssrn.com/abstract=1964782.

Corlu, M.S., Capraro, R.M., \& Capraro. M.M. (2014). Introducing STEM education: Implications for educating our teachers in the age of innovation. Education and Science, 39(171), 74-85.

(CXC) Caribbean Examinations Council. (2006). Caribbean Secondary Education Certificate: Chemistry Syllabuses. Jamaica: Author.

(CXC) Caribbean Examinations Council. (2008a). Caribbean Secondary Education Certificate: Information Technology. Jamaica: Author.

(CXC) Caribbean Examinations Council. (2008b). Caribbean Secondary Education Certificate: Mathematics. Jamaica: Author.

(CXC) Caribbean Examinations Council. (2010). Caribbean Secondary Education Certificate: Additional Mathematics. Jamaica: Author.

(CXC) Caribbean Examinations Council. (2012). Caribbean Secondary Education Certificate: Electronic Document Preparation and Management. Jamaica: Author.

(CXC) Caribbean Examinations Council. (2013a). Caribbean Secondary Education Certificate: Biology Syllabuses. Jamaica: Author.

(CXC) Caribbean Examinations Council. (2013b). Caribbean Secondary Education Certificate: Physics Syllabuses. Jamaica: Author.

(CXC) Caribbean Examinations Council. (2015a). Caribbean Secondary Education Certificate: Industrial Technology. Jamaica: Author.

(CXC) Caribbean Examinations Council. (2015b). Caribbean Secondary Education Certificate: Technical Drawing. Jamaica: Author.

Donovan, B.M., Mateos, D.M., Osborne, J.F., \& Bisaccio, D.J. (2014). Revising the Economic Imperative for US STEM Education. PLoS Biology, 12(1), e1001760. doi:10.1371/journal.pbio.1001760

Eberle, F. (2010). Why STEM education is important. Intech Magazine, September/October.

Emerson, E., Kiernan, C., Alborz, A., Reeves, D., Mason, H., Swarbrick, R., Mason, L., \& Hatton. C. (2001). The prevalence of challenging behaviors: a total population study. Research in Developmental Disabilities, 22(1), 77-93.

Evans C., McKenna, M., \& Schulte, B. (2013). Closing the Gap: Addressing STEM Workforce Challenges". EDUCAUSE Review, 48(3). Retrieved from http://www.educause.edu/ero/article/closing-gap-addressingstem-workforce-challenges.

Griffith, S.A. (2013a). Choice and Performance in CSEC and CAPE TVET Subjects: A Comparison with More Conventional Subjects. Caribbean Curriculum, 21, 97-119.

Griffith, S.A. (2013b). The Impact and Influence of CXC on the Regional Education Landscape. The Caribbean Examiner, 11(1), 16-19.

Jang, H. (2016). Identifying 21st century STEM competencies using workplace data. Journal of Science Education and Technology, 25(2), 284-301.

Joyce, A. (2014). Stimulating interest in STEM careers among students in Europe: Supporting career choice and giving a more realistic view of STEM at work. Paper presented at the 3rd Education and Employers Taskforce Research Conference: Exploring School-to-Work Transitions in International Perspectives. London, England. Retrieved from http://www.educationandemployers.org/wp-content/uploads/2014/06/joyce_-stimulating_interest_in_stem_careers_among_students_in_europe.pdf

Krokstad, S., Kunst, A.E., \& Westin. S. (2002). Trends in health inequalities by educational level in a Norwegian total population study. Journal of Epidemiology and Community Health, 56(5), 375-380.

Kudenko, I., \&. Gras-Velázquez. A. (2014). The future of European STEM workforce: What do secondary school pupils of Europe think about stem industry and careers. Brussels: Myscience.

Kuenzi, J. J. (2008). Science, Technology, Engineering, and Mathematics (STEM) Education: Background, Federal Policy, and Legislative Action. Retrieved from http://digitalcommons.unl.edu/cgi/viewcontent. cgi?article $=1034 \&$ context $=$ crsdocs.

Kyaga, S., Lichtenstein, P., Boman, M., \& Landen. M. (2015). Bipolar disorder and leadership - a total population study. Acta Psychiatrica Scandinavica, 131(2), 111-119.

Lacey, T.A., \&. Wright. B. (2009). Occupational employment projections to 2018. Monthly Labor Review, 132(11), $82-123$. 
Langstrom, N., Frisell, T., \& Lichtenstein. P. (2011). Familial aggregation of sexual offending: Total population study of 21,000 convicted men 1973-2009. Behavior Genetics, 41(6), 919-919.

Mercer-Blackman, V., \&. Melgarejo, K. (2013). Spillovers of global shocks over Caribbean countries: so large that there is little room to maneuver - an impulse response analysis. Inter-American Development Bank, Country Department, Caribbean Group, Policy Brief No. IDB-PB-206. Retrieved from https://publications.iadb.org/ handle/11319/1525.

Merchant, S., Morimoto, E. T.A., \& Khanbilvardi, R. (2014). An Integrated STEM Learning Model for High School in Engineering Education. Paper presented at the 4th IEEE Integrated STEM Education Conference, Princeton, NJ, March 8.

Ministry of Education, Jamaica. (n.d.) Establishing STEM Academies and Incorporating STEM methodologies in schools.

National Academy of Sciences, National Academy of Engineering, \& Institute of Medicine. (2011). Rising above the gathering storm revisited: Rapidly approaching category 5: Condensed version. Washington, DC: The National Academies Press.

(OECD) Organisation for Economic Co-operation and Development. (2010). The OECD innovation strategy: Getting head start on tomorrow. Retrieved from http://www.oecd.org/dataoecd/3/14/45302349.pdf

Padro, F. (2010). Policy Interests Driving Promotion of STEM Programs at Higher-Education Institutions. ASQ Education Brief, February. Retrieved from http://rube.asq.org/edu/2010/02/engineering/policy-interestsdriving-promotion-of-stem-programs-at-higher-education-institutions-.pdf.

Pawloski, J., Maas, S., Meyers, K., Standridge, C. \& Plotkowski, P. (2010). The Role of an Engineering College in Integrated K-12 STEM Outreach Efforts, ASQ Education Brief. Retrieved from http://asq.org/edu/2010/02/ engineering/the-role-of-an-engineering-college-in-integrated-k-12-stem-outreach-efforts-.pdf.

Ritz, J.M. \& Fan, S. (2015). STEM and technology education: international state-of-the-art. International Journal of Technology and Design Education, 25(4), 429-451

Rohaan E. J., Taconis, R., \& Jochems, W. (2010). Reviewing the relations between teachers' knowledge and pupils' attitude in the field of primary technology education. International Journal of Technology and Design Education, 20(1), 15- 26.

Sanders, M. (2009). STEM, STEM Education, STEMmania. Technology Teacher, 68(4), 20-26.

(UN) United Nations (2013). World Economic Situation and Prospects 2013. New York: UN.

(UNESCO) United Nations Educational, Scientific and Cultural Organization. (2009). World Conference on Higher Education: The New Dynamics for Higher Education and Research for Societal Change and Development. Communique, Paris: UNESCO, July.

U.S. Department of Education (2010). U.S. Education Secretary Arne Duncan Issues Statement on the Release of the President's Council of Advisors on Science and Technology (Pcast) K-12 STEM Education Report, September 16. Retrieved from http://www.ed.gov/news/press-releases/us-education-secretary-arne-duncan-issuesstatement-release-presidents-council-advisors-science-and-technology-pcast-k-12-stem-education-report.

Warde, C. \& Sah, D. ( 2014). Stem education reform considerations for the Caribbean. Business Barbados, (17th edition). Retrieved from http://businessbarbados.com/trending/entrepreneurship/stemeducation-reformconsiderations-caribbean/

World Bank. (2013). Quality education counts for skills and growth. Caribbean Knowledge Series. Author. Retrieved from http://worldbank.org/lac. 